\title{
ARTICLE
}

\section{A Study on the Representative Person of Critical Group for Radiological Assessment in Korea}

\author{
Gab-Bock Lee ${ }^{1 *}$, Doo-Ho Lee ${ }^{1}$, Yang-Hee Yang ${ }^{1}$, Young-Sik Jang ${ }^{2}$, Jong-Yi Moon ${ }^{3}$ \\ ${ }^{1}$ Korea Electric Power Research Institute, KEPCO, 65 Moonji-Ro, Yuseong-Gu, Daejeon 305-380, Korea \\ ${ }^{2}$ Korea Hydro \& Nuclear Power Co. Ltd., 411 Youngdong-Daero, Gangnam-Gu, Seoul 135-791, Korea \\ ${ }^{3}$ LKorea Institute of Nuclear Safety, 34 Gwahak-Ro, Yuseong-Gu, Daejeon 305-338, Korea
}

\begin{abstract}
The 'maximum individual' concept based on US NRC Regulatory Guide 1.109 has been used for the public dose calculation in Korea. However, the 'maximum individual' results in largely overestimating the public dose. In Korea, the adoption of the 'representative person' is under consideration. The 'representative person' was recommended by ICRP Publication No. 101. In this study, individual habits (consumption of foodstuffs, use of local resources) of representative person have been analyzed or investigated. The age-specific food consumption rates of the representative person were derived from the Korean national dietary survey by government in 2005 . The foodstuffs are classified into 12 classes - grain, fruits, kimchi, vegetables, milk, beef, pork, poultry, fishes, mollusca, crustacea, and seaweeds. The use of local resources such as the self-sufficiency of foodstuffs was investigated by using the questionnaire survey to the public members within $2 \mathrm{~km}$ from four nuclear power plant sites in Korea. The $95^{\text {th }}$ percentile values are used for the top-two pathways such as grain and kimchi, but the average values are used for other foods. The results show that the effective dose from new habit data is about $30 \%$ lower than that from the existing data.
\end{abstract}

\section{KEYWORDS: off-site dose, representative person, food consumption, food contamination fraction, habit data}

\section{Introduction}

The public dose assessment has been annually performed to confirm the radiation safety of the public around nuclear power plants (NPPs) in Korea. The internal dose by the food intake accounts for over $50 \%$ of the total effective dose of the public member.

The 'maximum individual' concept based on US NRC Regulatory Guide $1.109^{1)}$ has been used for the public dose calculation in Korea. However, the maximum individual may result in extremely overestimating the public dose.

Habit Data of the maximum individual from the field survey results around Kori NPP site from 1987 to 1988 have been used in assessing the dose calculation of residents around all NPPs (Ulchin, Wolsong, Kori, and Yonggwang sites) in Korea. The food consumption rates of the maximum individual were obtained by mean values of total 10 households which showed the most consumption rates among the 800 households within $80 \mathrm{~km}$ from Kori site. ${ }^{2)}$

Recently, Korean Hydro \& Nuclear Power Corporation (KHNP) plans to adopt the 'representative person' of critical group recommended by ICRP. 3 )

Therefore, the study on the re-establishment of the habit data such as food consumption rates and food contamination ratios are necessary for reflecting the recent change of the Korean dietary characteristics and for applying the representative person concept.

In this study, food consumption rates were newly suggested by using the national dietary survey results carried out by Korean ministry of Health, Wealth and Family Affairs

*Corresponding Author, E-mail:gblee@kepco.co.kr

(C) Atomic Energy Society of Japan in 2005. The food contamination ratios by food item were also analyzed from the national statistics and the field survey around nuclear power plant sites.

\section{Representative Person of Critical Group}

According to the ICRP-101, the representative person is equivalent to, and replaces, the average member of the critical group recommended by ICRP-43 ${ }^{4}$. In the ICRP-101, it is important that individual habits used in the deterministic approach are average habits of a small number of individuals who are representative of those more highly exposed, not the extreme habits of a single member of the population.

In addition, ICRP recommend that, if more than one intake route for radionuclides provides a significant contribution to dose, it may not be reasonable to assume that the $95^{\text {th }}$ percentile habit data are applicable to all routes: a $95^{\text {th }}$ percentile intake should be assigned to the more dominant routes, and a lower value should be assigned to other pathways.

In this study, the person who lives at the site boundary and has the most highly contaminated foods was considered as the representative person of the critical group. Food items were classified into 12 groups - grains, kimchi, vegetables, fruits, milk, beef, pork, poultry, fishes, mollusca, crustacea, and seaweeds.

The top-two food items were selected as the dominant pathways. UK Ministry of Agriculture, Fisheries and Food suggested that there was evidence from national and regional habit surveys that people rarely consumed more than two foods at high rates. ${ }^{5)}$

In this study, critical groups were indicated by job producing foodstuffs because doses by food ingestion 
account for above $50 \%$ of total off-site doses in Korea. Nuclear power plant sites are located at the rural and coastal region. Therefore, farmer and fisherman are likely to be highly exposed. Grains and vegetables were selected as the top-two food items for farmer, and fishes and seaweed for fisherman. The top-two foods were assigned

Ages for dose calculation were classified into 6 groups based on ICRP-60: 3-month, 1-, 5-, 10-, 15- year, and adult age groups. ${ }^{6}$

\section{Food Consumption Rates}

Age-specific food consumption rates of the representative person were analyzed from the raw data of national dietary survey. The nationwide dietary survey has been carried out every 3 years by Korean Ministry of Health, Wealth and Family Affairs. The recent survey released its raw data to the public were performed in 2005 . The sample size was 8,930 persons and the 24 hour-recall method was used. Table 1 illustrates the number of samples by age group.

Table 1. Number of Samples by Age Group base on ICRP-60

\begin{tabular}{|c|c|c|}
\hline Age group & Age & Samples \\
\hline 3 month & from 0 to 1 year of age & $67^{*}$ \\
\hline 1-year & from 1 to 2 year & 111 \\
\hline 5-year & more than 2 to 7 year & 631 \\
\hline 10-year & more than 7 to 12 year & 767 \\
\hline 15-year & More than 12 to 17 year & 716 \\
\hline Adult & More than 17 year & 6,705 \\
\hline
\end{tabular}

*) 3 month infant was surveyed in $2001 \sim 2002$, but not in 2005 .

The recent trends of food consumption rates from national dietary surveys since 1989 are illustrated in Fig. 1. Total consumption rate per person in 2005 increases about $30 \%$ in comparison with that of 1989 . Consumption rates of vegetables, fruits, milk and meat have increased, but consumption rates of grains and seafood have been in a steady-state.

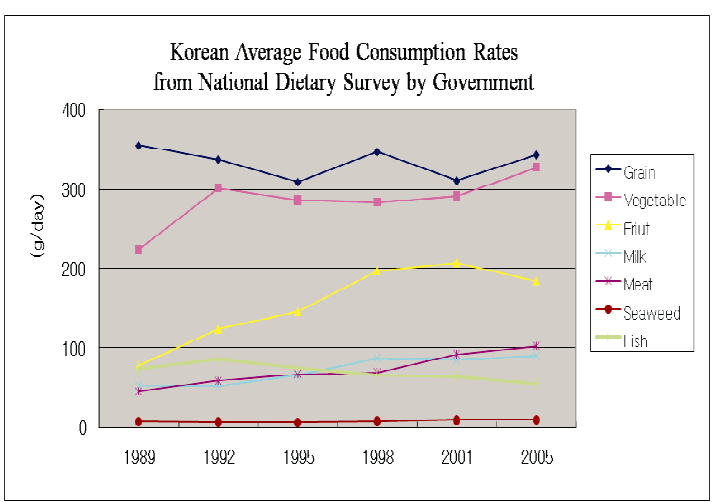

Fig. 1. Average Food Consumption Rates per Person in Korea

Age specific mean and $95^{\text {th }}$ percentile values of 12 food groups were analyzed to determine the food consumption rates of the representative person.
Table 2 illustrates the analysis results for adult and 5-year infant. Total average food consumption rate excluding milk was about $1 \mathrm{~kg} /$ day for adult and $0.5 \mathrm{~kg} /$ day for 5 -year infant.

$95^{\text {th }}$ percentile values were $2 \sim 7$ times as large as average values as the food item. The ratios of $95^{\text {th }}$ percentile to average value of main (or staple) food items were relatively small. The main food items were grains, vegetables, and kimchi for adult, grains, milk, and vegetables for infant. The 'kimchi' means Korean traditional food made of radish or Chinese cabbage. Consumption rates of the seafood such as fishes, seaweeds were relatively small.

If the $95^{\text {th }}$ percentile habit data are assigned to all routes, the public dose may be overestimated due to subsidiary food items having large standard deviations but relatively small average consumption rates.

Table 2. Food Consumption Rates by Foodstuff (unit : g/day)

\begin{tabular}{|c|c|c|c|c|}
\hline \multirow{2}{*}{$\begin{array}{c}\text { Food } \\
\text { Item }\end{array}$} & \multicolumn{2}{|c|}{ Adult } & \multicolumn{2}{c|}{ 5-year Infant } \\
\cline { 2 - 5 } & Average & $\begin{array}{c}95^{\text {th }} \\
\text { Percentile }\end{array}$ & Average & $\begin{array}{c}95^{\text {th }} \\
\text { Percentile }\end{array}$ \\
\hline Grain & 291.9 & 544.5 & 178.5 & 339.1 \\
\hline Kimchi & 145.9 & 373.3 & 38.9 & 141.6 \\
\hline Vegetables & 222.9 & 574.9 & 85.4 & 244.8 \\
\hline Fruit & 87.5 & 451.6 & 73.1 & 323.8 \\
\hline Beef & 20.5 & 106.8 & 10.5 & 58.1 \\
\hline Pork & 36.7 & 200.0 & 18.4 & 100.8 \\
\hline Poultry & 38.5 & 167.5 & 35.3 & 124.2 \\
\hline Fish & 43.7 & 200.0 & 14.8 & 73.4 \\
\hline Crustacea & 10.4 & 57.5 & 4.2 & 28.8 \\
\hline Mollusca & 8.7 & 55.3 & 4.1 & 28.3 \\
\hline Seaweed & 10.3 & 60.0 & 4.8 & 22.6 \\
\hline Sub total & 917.1 & 1743.7 & 468.1 & 947.2 \\
\hline Fresh milk & 42.5 & 200.5 & 171.9 & 505.2 \\
\hline
\end{tabular}

\section{Food Contamination Fraction}

At present, food contamination fractions from US NRC Regulatory Guide 1.109 have been used to calculate the off-site dose around nuclear power plant sites in Korea. However, these values may not be applicable to nuclear power sites in Korea because of the difference of the environmental characteristics.

In this study, food contamination fractions were re-established. Three factors were considered: the growing and storing period of the farm produce, the contamination ratios of livestock's feed, and the self-sufficiency of foodstuffs.

Growing and storing periods of foods were investigated by interviewing experts working at the agricultural technology centers around nuclear power sites. Results are illustrated in Table 3.

The annual portion of growing and storing period of grain which is the main food of Korean is set to 1.0 because the growing period of grain is about 6 months but the storing period is over 1year. The annual portion of vegetables is set to 0.5 , and that of fruits is set to 0.6. Growing and storing periods of these foods are relatively small. 
Table 3. Growing and Storing Period and Annual Fractions

\begin{tabular}{|c|c|c|c|}
\hline \multirow{2}{*}{ Food Item } & \multicolumn{2}{|c|}{ Period (unit : month) } & Annual \\
\cline { 2 - 3 } & Growing & Storing & Fraction \\
\hline Rice & 6 & 12 & 1.0 \\
\hline Barley & 8 & 12 & 1.0 \\
\hline Bean & 5 & 12 & 1.0 \\
\hline Vegetables & 4 & 2 & 0.5 \\
\hline Fruit & 6 & 2 & 0.6 \\
\hline
\end{tabular}

The contamination fractions of livestock fodder were analyzed from the statistical data of Korean Ministry for Food, Agriculture, Forestry and Fisheries. The cow's feed consist of the concentrated (or assorted) fodders and pastures (including rice straw), and the pig's feed are mainly the concentrated (or assorted) fodders.

The ratios of domestic products were considered as the contamination fractions of livestock fodder. $60 \%$ of the fodder for cow, and $70 \%$ for pig have been imported in the recent 5 years.

The self-sufficiency fractions of foods were surveyed around nuclear power plant sites. The survey overview is illustrated at Table 4. The self-sufficiency fractions include not only the self-producing foods but also the purchasing foods from the neighborhood.

Table 4. Survey outline of the food self-sufficiency fractions

\begin{tabular}{|c|c|}
\hline Item & Content \\
\hline Population & $\begin{array}{c}\text { Population within 2km from } 4 \\
\text { nuclear power plant sites in Korea }\end{array}$ \\
\hline Sample size & 800 persons \\
\hline Confidence level & $95 \%$ \\
\hline Sampling error & $\pm 3.3 \%$ \\
\hline Survey method & One to one interview \\
\hline Survey tool & Structured questionaire \\
\hline Survey period & $2008.12 \sim 2009.01$ \\
\hline
\end{tabular}

The statistics were analyzed by job - farmer and fisherman. Mean and $95^{\text {th }}$ percentile values of the food self-sufficiency fractions are illustrated in Fig. 2.

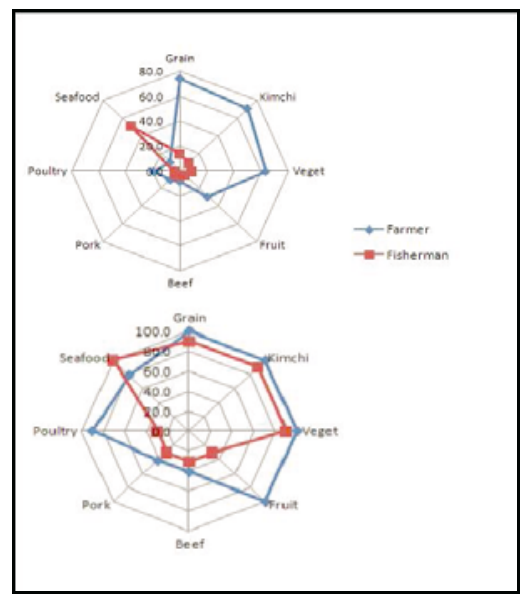

Fig. 2. Mean and $95^{\text {th }}$ percentile values of the food self-sufficiency fractions (the upper: average, the lower: $95^{\text {th }}$ percentile).
The average self-sufficiency fractions of meat, fruit, and seafood were very small, but those of grain and vegetables were relatively large for respondents of farmer. However, the average self-sufficiency fractions of agricultural products were very small, but that of seafood was relatively large for respondents of fisherman.

However, the $95^{\text {th }}$ percentile values of self-sufficiency fractions of seafood, poultry and fruit for farmer were dramatically increased in comparison with average values. The self-sufficiency fractions of grain, vegetables and kimchi for fisherman were also largely increased similar with farmer. These results imply that the assumption which the $95^{\text {th }}$ percentile habit data are applicable to all routes may lead to overestimate the dose of the public around nuclear power plant sites.

The integrated contamination fraction of foods were illustrated Table 5.

Table 5. The Proposed Food Contamination Fractions

\begin{tabular}{|c|c|c|c|c|c|}
\hline \multirow{2}{*}{ Food } & \multirow{2}{*}{$\begin{array}{c}\text { Existing } \\
\text { value }\end{array}$} & \multicolumn{3}{|c|}{ Proposed value in this study } \\
\cline { 3 - 6 } & & $95^{\text {th }}$ & Mean & $95^{\text {th }}$ & Mean \\
\hline Grain & 0.90 & 1.00 & 0.74 & 0.90 & 0.14 \\
\hline Kimchi & 0.76 & 0.50 & 0.36 & 0.45 & 0.05 \\
\hline Vegetables & 1.00 & 0.50 & 0.32 & 0.45 & 0.05 \\
\hline Fruit & 1.00 & 0.70 & 0.20 & 0.21 & 0.04 \\
\hline Beef, Milk & 1.00 & 0.16 & 0.03 & 0.12 & 0.02 \\
\hline Pork & 1.00 & 0.13 & 0.03 & 0.09 & 0.01 \\
\hline Poultry & 1.00 & 0.90 & 0.19 & 0.30 & 0.04 \\
\hline Seafood & 1.00 & 0.60 & 0.10 & 1.00 & 0.35 \\
\hline
\end{tabular}

Grains and vegetables were assigned $95^{\text {th }}$ percentile values for farmer, and other foods were assigned average values. For fisherman, Seafood was assigned $95^{\text {th }}$ percentile values.

\section{Analysis of Impact to Dose}

Off-site doses were calculated to analyze the impact of the habit data change. ${ }^{3} \mathrm{H},{ }^{14} \mathrm{C}$ and ${ }^{131}$ I were selected because doses due to these nuclides account for more than $90 \%$ of total effective dose during normal operation in Korea.

Ratios of doses by existing values to doses by newly proposed values are illustrated in Fig. 3. 'Max(1988)' in Fig. 3 means doses calculated by using the existing values of food consumption rates and food contamination fractions. 'Rep(Farmer)' and 'Rep(Fisherman)' mean doses calculated by using newly proposed data in this study.

Ingestion doses of representative person by newly suggested values for farmer and fisherman are decreased in comparison with those of the existing maximum individual except for crop ingestion dose due to ${ }^{14} \mathrm{C}$. Total effective doses due to tritium and ${ }^{131} \mathrm{I}$ are largely decreased but doses by ${ }^{14} \mathrm{C}$ are slightly decreased. Although not illustrated in Fig. 3 , most of doses due to tritium and ${ }^{131}$ I result from ingestion of kimchi and vegetable, and dose by ${ }^{14} \mathrm{C}$ ingestion are from grain.

If newly suggested values of food consumption rates and contamination fractions for farmer are applied to dose calculation, the total effective doses of the public around 
nuclear power plant sites in normal operation may decrease approximately $30 \%$ compared with the present dose.

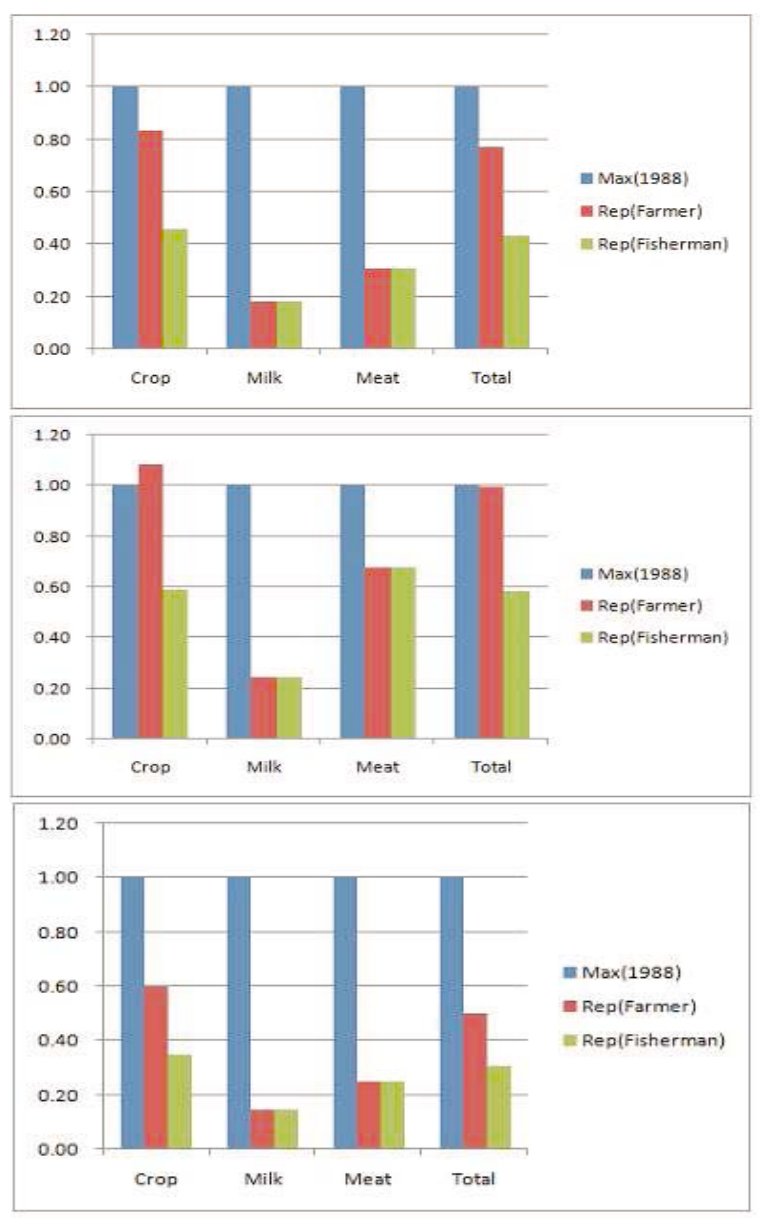

Fig. 3. Ratios of Doses by Existing Values to Those by Newly Proposed Values (Top: ${ }^{3} \mathrm{H}$, Middle: ${ }^{14} \mathrm{C}$, Bottom: ${ }^{131} \mathrm{I}$ ).

\section{Conclusion}

In Korea, the 'maximum individual' concept based on US NRC Regulatory Guide 1.109 has been used for assessing radiological dose calculation.
To less conservatively assess off-site dose, adoption of the 'representative person' recommended by ICRP Publication 101 has been considered by nuclear utility, KHNP (Korea Hydro \& Nuclear Power Co.).

In this study, dietary habit data of the representative person such as food consumption rates and food contamination fractions are newly suggested from national statistical data and field surveys. Newly proposed data may contribute to mitigate the conservatism in the off-site dose calculation.

Hereafter, dietary habit data for radiological assessment may be periodically updated cost-effectively by using national dietary survey results carried out every 3 years by government.

\section{References}

1) US Nuclear Regulatory Commission, Calculation of annual doses to man from routine releases of reactor effluents for the purpose of evaluating compliance with 10CFR Part 50, Appendix I, Regulatory Guide 1.109 Revision 1, 1 (1977).

2) J.H. Lee et al., Overall Environmental Evaluation around Kori Nuclear Power Plant Site and the Development of its Model - Appendix III. Survey Results of Environmental Characteristics, KAERI/NSC-397/89, Korea Atomic Energy Research Institute, 4-7 (1989). (in Korean)

3) International Commission on Radiological Protection, Assessing dose of the representative person for the purpose of radiation protection of the public, ICRP Publication 101, Part 1, 23 (2006).

4) International Commission on Radiological Protection, Principles of monitoring for the radiation protection of the public, ICRP Publication 43, 3 (1984).

5) Environment Agency(UK), Authorization of discharges of radioactive waste to the environment-Principles for the assessment of prospective public doses, Interim Guidance, 25 (2002).

6) International Commission on Radiological Protection, Age-dependent doses to members of the public from intake of radionuclides: Part 2 Ingestion dose coefficients, ICRP Publication 67, 4 (1993). 